\title{
Brain and Pineal 7a-Hydroxypregnenolone Regulating Locomotor Behavior: Discovery, Progress and Prospect
}

\author{
Kazuyoshi Tsutsui ${ }^{1,+}$, Shogo Haraguchi ${ }^{1,2}$ and Takayoshi Ubuka'
}

\begin{abstract}
The brain synthesizes steroids de novo from cholesterol, which are called neurosteroids. The formation of neurosteroids in the brain is a conserved property across vertebrates, but it is still incompletely elucidated in vertebrates. In fact, 7a-hydroxypregnenolone (7a-OH PREG) was identified as a novel bioactive neurosteroid stimulating locomotor behavior in the brain of several vertebrates. Subsequently, the mode of action of 7a-OH PREG and the regulation of 7a-OH PREG synthesis in the brain have demonstrated by follow-up studies. Recently, it has been demonstrated that the pineal gland, an endocrine organ located close to the brain, is a major site of formation of bioactive neurosteroids. This is a new finding of the formation of neurosteroids because for a long time neurosteroids are believed to be produced in neurons and glial cells in the brain. In addition to the brain, the pineal gland actively produces $7 \mathrm{a}-\mathrm{OH}$ PREG as a major pineal neurosteroid that acts on the brain to regulate locomotor rhythms. Thus, the discovery of 7a-OH PREG, a new bioactive neurosteroid, has provided a novel direction to investigate neurosteroid regulation of locomotor behavior. This review summarizes the discovery, progress and prospect of brain and pineal 7a-OH PREG regulating locomotor behavior in vertebrates.
\end{abstract}

\section{Keywords}

7a-hydroxypregnenolone (7a-OH PREG), Dopamine, Melatonin, Prolactin, Corticosterone, Brain, Pituitary gland, Pineal gland

\begin{abstract}
Introduction
Extensive studies over the past thirty years have demonstrated that the brain produces steroids de novo from cholesterol (CHOL). Such steroids are called neurosteroids that regulate several brain functions, such as neuronal proliferation, activity and survival, and behavioral and neuroendocrine processes for reviews, see [1-9]. The formation of bioactive neurosteroids in the brain is a conserved property across vertebrates from mammals to fish [10-52]. However, the formation of bioactive neurosteroids in the brain is still incompletely elucidated in vertebrates for a review, see [5]. In
\end{abstract}

fact, $7 \alpha$-hydroxypregnenolone ( $7 \alpha$-OH PREG) was identified as a novel bioactive neurosteroid stimulating locomotor behavior in the brain of various vertebrates, such as newts $[41,53]$, quail [54] and fish [55] at the beginning of 2000s. The follow-up studies over the past decade have demonstrated that $7 \alpha-\mathrm{OH}$ PREG produced in the brain of these vertebrates plays an important role in the regulation of locomotor behavior via the dopaminergic system for reviews [56-62].

On the other hand, it has been demonstrated that the pineal gland, an endocrine organ located close to the brain, actively produces various

'Laboratory of Integrative Brain Sciences, Department of Biology and Center for Medical Life Science, Waseda University, Tokyo 1628480, Japan

${ }^{2}$ Department of Biochemistry, Showa University School of Medicine, Tokyo 142-8555, Japan

${ }^{\dagger}$ Author for correspondence: Kazuyoshi Tsutsui, Ph.D., Professor, Laboratory of Integrative Brain Sciences, Department of Biology, Waseda University, Center for Medical Life Science of Waseda University, 2-2 Wakamatsu-cho, Shinjuku-ku, Tokyo 162-8480, Japan, Tel: 81-3-5369-7311; Fax: 81-3-3355-0316, email: k-tsutsui@waseda.jp 
neurosteroids de novo from CHOL [63,64] at the beginning of 2010s. This is a new concept of neurosteroid formation because for the past thirty years neurosteroids were believed to be produced de novo from CHOL in neurons and glial cells in the brain for reviews [1-9]. Importantly, pineal $7 \alpha-\mathrm{OH}$ PREG is actively secreted as a major pineal neurosteroid from the pineal gland and acts on the brain to control locomotor rhythms $[63,64]$.

Herein we review the discovery, progress and prospect of brain and pineal $7 \alpha-\mathrm{OH}$ PREG regulating locomotor behavior in vertebrates based on new findings obtained by recent studies.

\section{Discovery of Brain and Pineal 7a-OH PREG Regulating Locomotor Behavior}

\section{- Identification of brain 7a-OH PREG stimulating locomotor activity}

At the beginning of 2000 s, it was found that the brain of newts [41] and quail [54] actively produces $7 \alpha-\mathrm{OH}$ PREG, a previously unknown neurosteroid, de novo from CHOL in these vertebrates, by biochemical techniques combined with high-performance liquid chromatography (HPLC) and gas chromatography-mass spectrometry (GC-MS). It was also found that the brain of salmon actively produces $7 \alpha-\mathrm{OH}$ PREG de novo from CHOL [55]. Subsequently, cytochrome P450 7 $\alpha$-hydroxylase (cytochrome $\mathrm{P} 450_{7 \alpha}$ ), which produces $7 \alpha-\mathrm{OH}$ PREG from pregnenolone (PREG), was identified in the brain of these vertebrates $[42,54,55]$ and demonstrated its enzymatic activity by HPLC and GC-MS using COS-7 cells transfected with the identified cytochrome P450 $0_{7 \alpha}$ cDNA $[42,54,55]$. Because $7 \alpha-\mathrm{OH}$ PREG is also produced in the brain of mammals [30,65-68], the production of $7 \alpha-\mathrm{OH}$ PREG in the brain is considered to be a conserved property across vertebrates (Figure 1).

Soon after the identification of $7 \alpha-\mathrm{OH}$ PREG in the brain, the biological action of brain $7 \alpha-\mathrm{OH}$ PREG was investigated in newts by analyzing locomotor behavior because $7 \alpha-\mathrm{OH}$ PREG is actively synthesized in the diencephalon and rhombencephalon in the brain of newts [41] and quail [54]. Intracerebroventricular (ICV) injection of $7 \alpha-\mathrm{OH}$ PREG increases locomotor activity of newts [41] and quail [54]. Based on these findings $[41,54]$, it is considered that brain $7 \alpha-\mathrm{OH}$ PREG acts on the brain to stimulate locomotor activity in newts and quail for reviews, see [56-61]. Subsequently, the biological action of brain $7 \alpha-\mathrm{OH}$ PREG on upstream migratory behavior was investigated in salmon [55] because

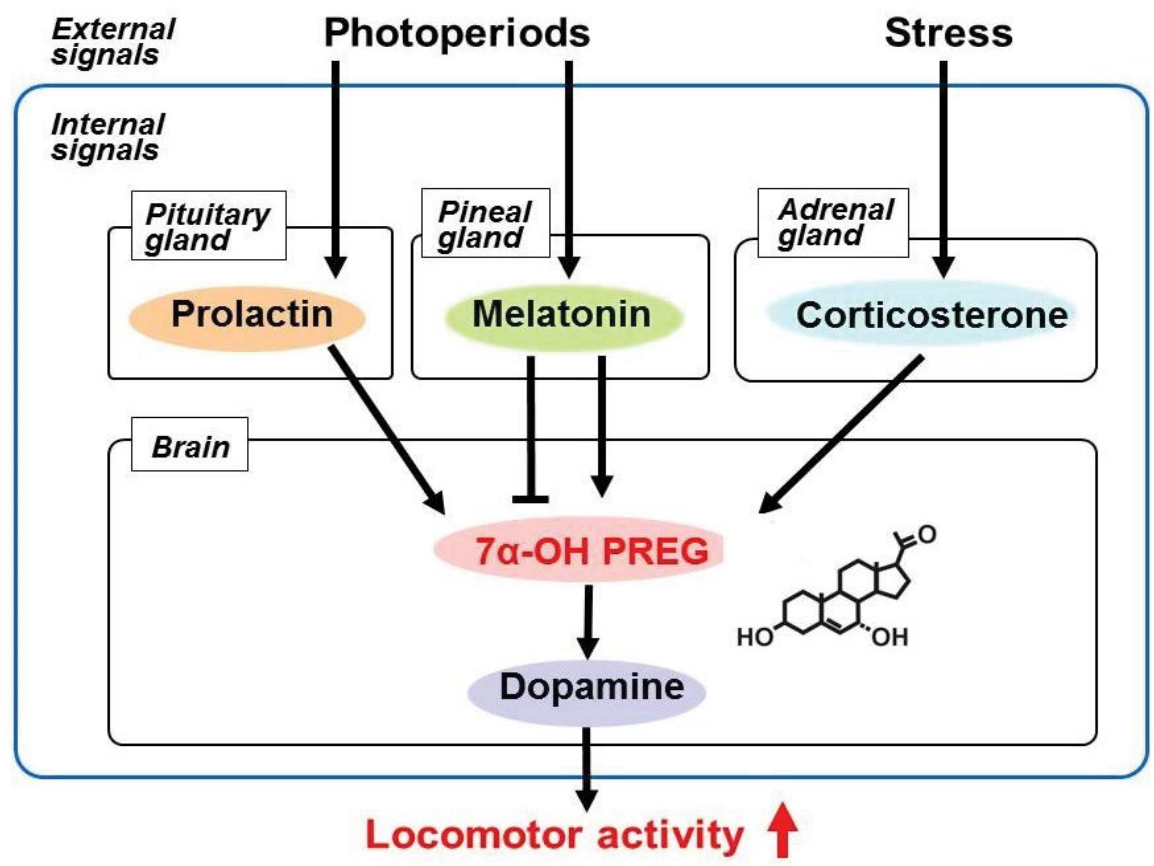

Figure 1: Mode of action and regulation of biosynthesis of brain 7a-OH PREG. 7a-OH PREG produced in the brain stimulates locomotor activity via the dopaminergic system in the brain. 7a-OH PREG synthesis in the brain is regulated by pineal melatonin, pituitary prolactin and adrenal corticosterone. Modified from Tsutsui et al., Matsunaga et al., Tsutsui et al. and Haraguchi et al. [41,53-61,89]. 
locomotor activity of salmon increases during upstream migration against an opposing current in their natal river [69-71]. Interestingly, $7 \alpha-\mathrm{OH}$ PREG synthesis in the salmon brain increases during upstream migration and brain $7 \alpha-\mathrm{OH}$ PREG stimulates upstream migratory behavior of salmon [55]. Thus, these findings indicate the stimulatory action of brain $7 \alpha-\mathrm{OH}$ PREG on locomotor behavior in various vertebrates (Figure 1).

\section{- Identification of pineal 7a-OH PREG regulating locomotor rhythms}

It is well known that the pineal gland, an endocrine organ located close to the parietal region of the brain, transduces photoperiodic changes to the neuroendocrine system by rhythmic melatonin secretion in vertebrates for reviews, see $[61,62,72]$. Until recently, there was no report indicating the formation of neurosteroids in the pineal gland in any vertebrate. Importantly, at the beginning of 2010s, it has been demonstrated that the pineal gland is a major site of neurosteroidogenesis and actively produces a variety of neurosteroids de novo from CHOL in birds [63,64]. The discovery of pineal neurosteroids has built a new concept of the formation of neurosteroids because for the past thirty years neurosteroids are believed to be produced in neurons and glial cells in the brain for reviews, see [1-9].

In vertebrates, PREG, a common precursor of all steroid hormones, is formed by cleavage of the side-chain of CHOL by cytochrome P450scc. It was first found that the pineal gland of juvenile chickens and quail highly expresses cytochrome P450scc by RT-PCR analysis. It was further found that the pineal gland of these juvenile birds produces PREG from CHOL by HPLC and GC-MS analyses [63,64] (Figure 2). In addition, immunohistochemical analysis showed that cytochrome P450scc is localized in pinealocytes [63].

It was further clarified that the pineal gland of juvenile chickens [64] and quail [63] expresses other steroidogenic enzymes, such as cytochrome $\mathrm{P} 450_{7 \alpha}, 3 \alpha$ - and $3 \beta$-hydroxysteroid dehydrogenase $/ \Delta^{5}-\Delta^{4}$-isomerase $(3 \alpha-\quad$ and $3 \beta$-HSD), $5 \alpha$ - and $5 \beta$-reductase, cytochrome P450 17 $\alpha$-hydroxylase/c17,20-lyase (cytochrome $\left.\mathrm{P} 450_{17 \alpha \text {,lyase }}\right)$, 17 $\beta$-hydroxysteroid dehydrogenase (17 $\beta$-HSD) and cytochrome P450 aromatase (cytochrome P450arom). Based on molecular and biochemical analyses, the biosynthetic pathways of neurosteroids was demonstrated in the pineal gland of these juvenile birds $[63,64]$. Thus, the pineal gland produces a variety of neurosteroids de novo from CHOL, such as PREG, $7 \alpha$ - and $7 \beta-O H$ PREG, progesterone

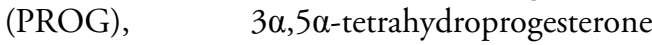
[3 $\alpha, 5 \alpha$-THP/allopregnanolone (ALLO)], androstenedione $(\mathrm{AD})$, testosterone $(\mathrm{T}), 5 \alpha$ - and $5 \beta$-dihydrotestosterone ( $5 \alpha$ - and $5 \beta-\mathrm{DHT})$, and estradiol-17 $\beta$ (E2) in juvenile birds (Figure 2).

By biochemical studies combined with HPLC and GC-MS analyses, it was further found that $7 \alpha-\mathrm{OH}$ PREG and ALLO are major pineal neurosteroids. PREG is converted primarily into $7 \alpha-\mathrm{OH}$ PREG and ALLO in the pineal gland and the production of these major pineal neurosteroids are higher in chicks than in adults. Surprisingly, $7 \alpha-\mathrm{OH}$ PREG and ALLO are actively produced in the pineal gland and these major pineal neurosteroid are released from the

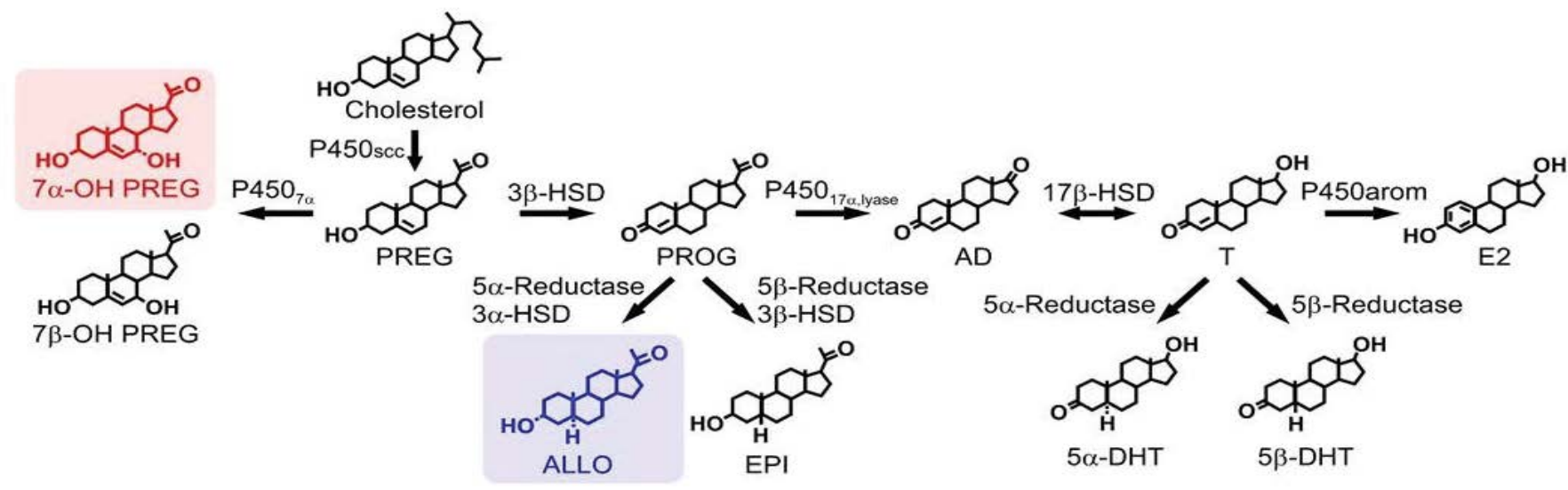

Figure 2: Biosynthetic pathways for pineal neurosteroids. The pineal gland expresses several key steroidogenic enzymes and produces various neurosteroids de novo from CHOL via PREG in juvenile birds. 7a-OH PREG and ALLO are major pineal neurosteroids that are secreted by the pineal gland and act on the brain. Modified from Haraguchi et al., Haraguchi et al. and Tsutsui et al. [61-63,72]. 
pineal gland of juvenile birds [63,64] (Figure 2). Subsequently, the biological action of pineal $7 \alpha$-OH PREG, a major pineal neurosteroid, was investigated in juvenile birds [64]. It has been demonstrated that pineal $7 \alpha-\mathrm{OH}$ PREG acts on the brain to regulate locomotor rhythms [54,64]. In addition, it has been demonstrated that the production of pineal $7 \alpha-\mathrm{OH}$ PREG is stimulated by light depending on the time-ofday for the regulation of locomotor rhythms for reviews [61,62,72]. Mode of action of pineal $7 \alpha$-hydroxypregnenolone regulating locomotor rhythms (Figure 3).

\section{Progression of 7a-OH PREG Research \\ - Regulation of the biosynthesis of brain 7a- OH PREG}

The mechanisms that regulate the biosynthesis of $7 \alpha-\mathrm{OH}$ PREG in the brain were then examined in vertebrates to understand the functional significance of brain $7 \alpha-\mathrm{OH}$ PREG in the regulation of locomotor activity.

It was investigated whether $7 \alpha-\mathrm{OH}$ PREG produced in the brain is involved in the regulation of diurnal locomotor changes because many vertebrates exhibit diurnal changes in locomotor activity for reviews, see $[61,62,72]$. Tsutsui et al. [54] found that male quail exhibit clear diurnal changes in locomotor activity and these changes occur in parallel with diurnal changes in $7 \alpha-\mathrm{OH}$ PREG synthesis and concentration in the diencephalon. Tsutsui et al. [54] further found that administration of ketoconazole, an inhibitor of cytochrome P450s, to male quail abolishes diurnal changes in locomotor activity. Accordingly, it is possible that brain $7 \alpha-\mathrm{OH}$ PREG controls diurnal changes in locomotor activity in male quail (Figure 1).

The pineal gland and eyes are known to regulate locomotor activity in birds [16,73-78]. Therefore, it was investigated whether melatonin regulates diurnal changes in brain $7 \alpha-\mathrm{OH}$ PREG synthesis and thereby induces diurnal changes in locomotor activity in male quail. Tsutsui et al. [54] found that the synthesis and concentration of $7 \alpha-\mathrm{OH}$ PREG increase in the brain of male quail after melatonin removal by pinealectomy (Px), combined with orbital enucleation (Ex). Conversely, the synthesis and concentration of $7 \alpha-\mathrm{OH}$ PREG decrease in the brain of male quail after the administration of melatonin [54]. Thus, it appears that melatonin secreted by the pineal gland and eyes inhibits brain $7 \alpha-\mathrm{OH}$ PREG synthesis in male quail [54] (Figure 1).

Quail is a diurnal animal and melatonin secretion is low during the light period. It is possible that the decrease in melatonin secretion during the light period induces an increase in brain $7 \alpha-\mathrm{OH}$ PREG synthesis, and consequently locomotor activity increases during the light period in the quail for reviews [56-58,62]. By contrast, the

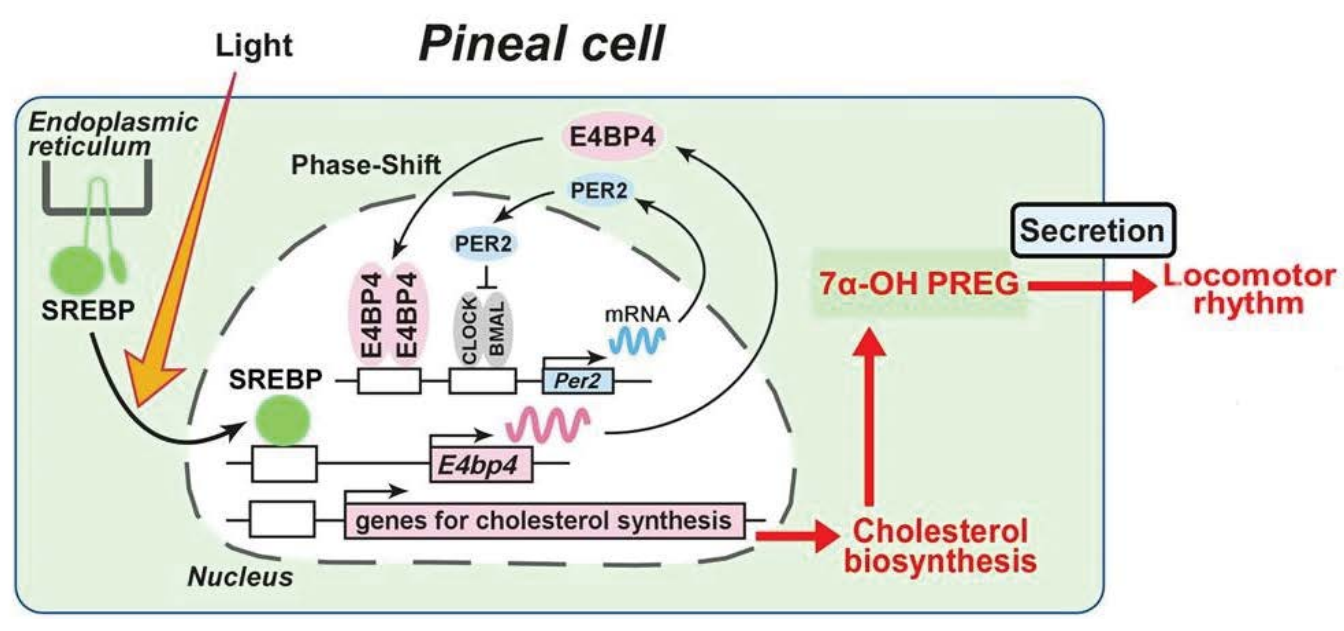

Figure 3: Mode of action and regulation of biosynthesis of pineal 7a-OH PREG. The circadian clock regulates daily locomotor rhythm in birds. The phase of the circadian clock is adjusted by the changes in light in a time-of-day-dependent manner in birds. A light pulse given at early night activates formation of the active form of SREBP, resulting in induction of a number of genes governing CHOL synthesis as well as a clock gene E4bp4. E4BP4 is a transcription factor that regulates the circadian clock through repression of clock gene Per2. SREBP-mediated induction of CHOL synthetic genes enhances the synthesis of $\mathrm{CHOL}$ and leads to the synthesis of 7a-OH PREG, a neurosteroid stimulating locomotor activity. Thus, the biosynthesis of pineal $7 \mathrm{a}-\mathrm{OH}$ PREG is stimulated by light depending on the time-of-day for the regulation of locomotor rhythms. Adapted from Tsutsui et al., Tsutsui et al., Hatori et al., and Tsutsui et al. [54,61-64,72]. 
synthesis and concentration of brain $7 \alpha-\mathrm{OH}$ PREG in the newt, a nocturnal animal, increases during the dark period when locomotor activity is high for reviews $[56-58,62]$. In contrast to the quail, melatonin stimulates the synthesis and concentration of brain $7 \alpha-\mathrm{OH}$ PREG in the newt for reviews $[56-58,62]$. Thus, the increase in melatonin secretion during the dark period increases brain $7 \alpha-\mathrm{OH}$ PREG synthesis, and consequently locomotor activity increases during the dark period in the newt, a nocturnal animal for reviews [56-58,62] (Figure 1).

Many migratory birds migrate at night, although most of them are diurnal outside the migratory seasons. Because during the migratory periods birds showing nocturnal migratory restlessness (Zugunruhe) have reduced melatonin concentrations at night than non-migratory periods, the involvement of melatonin on Zugunruhe has been hypothesized for reviews, see $[58,61]$. Because $7 \alpha-\mathrm{OH}$ PREG appears to control diurnal locomotor rhythms by the interaction of melatonin in birds, it is possible that reduction of melatonin in migratory period birds at night may affect $7 \alpha-\mathrm{OH}$ PREG synthesis in the brain to facilitate migratory activity of birds. Recently, it was founded that the concentration of brain $7 \alpha-\mathrm{OH}$ PREG increases during migration in white-crowned sparrows [Tsutsui et al., unpublished]. More detail analyses are in progress.

Seasonal changes in the synthesis of $7 \alpha-\mathrm{OH}$ PREG was further investigated in the brain of male newts $[41,53]$. It was found that $7 \alpha-$ $\mathrm{OH}$ PREG synthesis and cytochrome $\mathrm{P} 450_{7 \alpha}$ mRNA expression in the brain increase during the breeding season when locomotor behavior increases in male newts $[41,53]$. It is known that plasma concentrations of prolactin (PRL) and gonadotropins (GTHs) increase in male newts during the breeding season [78-81]. Therefore, Haraguchi et al. [53] manipulated the levels of PRL and GTHs and investigated the changes in brain $7 \alpha-\mathrm{OH}$ PREG synthesis in male newts. Hypophysectomy (Hypox) decreases $7 \alpha-\mathrm{OH}$ PREG synthesis and concentration in the brain, suggesting the involvement of PRL and/ or GTHs in the regulation of seasonal changes in brain $7 \alpha-\mathrm{OH}$ PREG synthesis [53]. ICV injection of PRL but not GTHs to male newts increases brain $7 \alpha-\mathrm{OH}$ PREG synthesis and concentration [53]. Thus, it appears that brain $7 \alpha-\mathrm{OH}$ PREG synthesis is regulated by PRL secreted by the anterior pituitary gland in male newts (Figure 1). Haraguchi et al. [53] further found that the neurons expressing cytochrome $\mathrm{P}_{450}$ in the diencephalon express PRL receptor in male newts. Accordingly, it is considered that pituitary PRL acts directly on neurons in the diencephalon to increase brain $7 \alpha-\mathrm{OH}$ PREG synthesis during the breeding period when locomotor activity increases in male newts for reviews, see [56-58,62] (Figure 1).

It is well known that in vertebrates acute stress increases the circulating glucocorticoid level [82-86] and changes locomotor behavior $[87,88]$. However, the mode of action of glucocorticoid on locomotor behavior is poorly understood. To clarify whether the increase in glucocorticoid concentration under acute stress changes the synthesis of brain $7 \alpha-\mathrm{OH}$ PREG, a series of experiments was conducted in male newts. Restraint stress increases brain $7 \alpha-\mathrm{OH}$ PREG synthesis and concentration concomitant with the increase in plasma concentrations of corticosterone (CORT) in newts [89]. Hypox decreases plasma CORT concentration and brain $7 \alpha$-OH PREG synthesis, whereas administration of CORT to Hypox newts increases brain $7 \alpha-\mathrm{OH}$ PREG synthesis [89]. Furthermore, glucocorticoid receptor (GR) is expressed in hypothalamic neurons expressing cytochrome $\mathrm{P} 50_{7 \alpha}$ [89]. Thus, it is considered that acute stress increases brain $7 \alpha-\mathrm{OH}$ PREG synthesis by the direct action of CORT on hypothalamic neurons via GR, thereby influences locomotor activity for a review [61] (Figure 1).

\section{- Mode of action of brain 7 $\alpha-O H$ PREG stimulating locomotor activity}

Subsequently, the mode of action of brain $7 \alpha-\mathrm{OH}$ PREG on the stimulation of locomotor behavior was elucidated in vertebrates. Matsunaga et al. [41] found that $7 \alpha-\mathrm{OH}$ PREG increases dopamine concentration in the striatum involved in the regulation of locomotor behavior in the newt. $7 \alpha-\mathrm{OH}$ PREG also increases the release of dopamine from cultured brain [41]. Matsunaga et al. [41] further found that administration of dopamine $\mathrm{D}_{2}$ receptor antagonists (haloperidol and sulpiride) abolishes the stimulatory action of $7 \alpha-\mathrm{OH}$ PREG on locomotor behavior [41]. Based on biochemical, morphological and behavioral analyses [41], it is considered that $7 \alpha$ $\mathrm{OH}$ PREG synthesized in the brain, by acting on dopaminergic neurons, induces dopamine release from their terminals, and consequently increases locomotor activity of newts [41]. Tsutsui et al. [54] also found a similar mode of action of brain $7 \alpha-\mathrm{OH}$ PREG on locomotor activity 
in the quail. Recently, Haraguchi et al. [55] further found that brain $7 \alpha-\mathrm{OH}$ PREG acts on dopamine neurons to induce dopamine release from their termini, and consequently stimulates upstream migratory behavior in the salmon. Thus, it appears that brain $7 \alpha-\mathrm{OH}$ PREG acts on the brain to stimulate locomotor activity via the dopaminergic system in these vertebrates for reviews, see [56-61] (Figure 1).

- Mode of action of pineal 7 $\alpha-O H$ PREG regulating locomotor rhythms

The circadian clock regulates daily locomotor rhythm in birds [90]. The phase of the circadian clock is adjusted by the changes in light in a timeof-day-dependent manner in birds [91]. The finding that the pineal gland of juvenile birds actively produces $7 \alpha-\mathrm{OH}$ PREG has contributed to understand the molecular mechanisms underlying light-dependent regulation of the circadian clock [64].

Because $7 \alpha-\mathrm{OH}$ PREG, a major pineal neurosteroid, is released from the pineal gland of juvenile birds [63,64] (Figure 2), this pineal neurosteroid may play an important role in the regulation of daily locomotor rhythm. Therefore, a series of experiments was conducted in juvenile birds. The light pulse given at early night stimulates the formation of the active form of sterol regulatory element-binding protein (SREBP) transcription factor and induces SREBP-target genes involved in CHOL synthesis in the pineal gland [91]. Based on this photic induction of SREBP-target genes that are involved in CHOL synthesis, light may upregulate $\mathrm{CHOL}$ synthesis in the pineal gland. Analysis of light-regulated genes in the chicken pineal gland gave the insight that the pineal gland actively produces and secretes $7 \alpha-\mathrm{OH}$ PREG [64] that increases locomotor behavior in birds [54]. Importantly, pineal $7 \alpha-\mathrm{OH}$ PREG synthesis is stimulated by a light pulse given at early night, but not at late night and daytime [64]. Furthermore, locomotor behavior of dark-reared juvenile birds is stimulated by light exposure more strongly at early night than at late night and daytime [64]. Furthermore, the light-dependent stimulation of locomotor behavior at early night is reduced by $\operatorname{Px}$ [64]. These findings [54,64] indicate that pineal $7 \alpha-\mathrm{OH}$ PREG synthesis is stimulated by light depending on the time-of-day for the regulation of locomotor rhythms for reviews, see [61,62,72] (Figure 3).
Future Prospects for 7a-OH PREG Research

Future prospects of brain 7a-OH PREG stimulating locomotor activity

Mode of action of brain $7 \alpha-\mathrm{OH}$ PREG stimulating locomotor activity, brain $7 \alpha$ $\mathrm{OH}$ PREG, a newly discovered bioactive neurosteroid, stimulates locomotor behavior in vertebrates. The stimulatory action of brain $7 \alpha-$ $\mathrm{OH}$ PREG on locomotor behavior is mediated by the dopaminergic system (Figure 1). Because brain $7 \alpha-\mathrm{OH}$ PREG stimulates locomotor behavior acutely, this bioactive neurosteroid may act on target cells by non-genomic mechanisms. The receptor for $7 \alpha-\mathrm{OH}$ PREG remains unclear although PREG binds receptors for $N$-methylD-aspartate (NMDA) and $\gamma$-aminobutyric acid A $\left(\mathrm{GABA}_{A}\right)$ for reviews, see $[61,62,72]$. Future studies are needed to clarify whether the acute action of brain $7 \alpha-\mathrm{OH}$ PREG on locomotor behavior is mediated through these receptors or an unknown membrane receptor for $7 \alpha-\mathrm{OH}$ PREG.

\section{- Future prospects of pineal 7 $\alpha-O H$ PREG} regulating locomotor rhythms

Identification of pineal $7 \alpha-\mathrm{OH}$ PREG regulating locomotor rhythms, neurosteroids are actively produced de novo from CHOL in the pineal gland of juvenile birds. This is a new concept of neurosteroidogenesis because we believed that neurons and glial cells in the brain and peripheral nervous system produce neurosteroids de novo from CHOL. Furthermore, mode of action of pineal $7 \alpha-\mathrm{OH}$ PREG regulating locomotor rhythms, $7 \alpha-\mathrm{OH}$ PREG, a major pineal neurosteroid, is considered to be a critical regulator of locomotor rhythms, connecting light-induced gene expression with locomotor behavior. Recent studies have demonstrated that the pineal gland of mice and zebrafish also produces $7 \alpha-\mathrm{OH}$ PREG actively (Tashiro, K., Tokita, T., Haraguchi, S., Tsutsui, K., unpublished observation). Therefore, future studies are needed to demonstrate the biological action of pineal $7 \alpha-\mathrm{OH}$ PREG in these vertebrates to clarify the generality of the findings in birds across vertebrates.

\section{- Application of basic research to clinical research}

Since $7 \alpha-\mathrm{OH}$ PREG synthesized in the brain increases locomotor activity by increasing dopamine release (Figure 1), decreased synthesis of $7 \alpha-\mathrm{OH}$ PREG in the brain may cause ataxia by decreasing locomotor activity. Furthermore, 
failure in $7 \alpha-\mathrm{OH}$ PREG synthesis in the brain is thought to be one of the causes of depression. On the other hand, as $7 \alpha-\mathrm{OH}$ PREG synthesized in the pineal gland regulates locomotor rhythm (Figure 3), the decrease in pineal $7 \alpha-\mathrm{OH}$ PREG synthesis may cause biological dysrhythmia. A clinical research that identifies deficits in brain function caused by disorders in brain and pineal $7 \alpha$-OH PREG synthesis is necessary. In addition, application of basic research in $7 \alpha-\mathrm{OH}$ PREG may contribute to treatments of depression and biological dysrhythmia. It has been shown that circadian rhythm sleep depressive disorders have alterations in melatonin receptor expression and melatonin production [92]. It is therefore possible that $7 \alpha-\mathrm{OH}$ PREG is the link between deficits in the melatonin signaling system and depression and biological dysrhythmia. It has also been known that disturbed rhythm and concentration of cortisol, an adrenal steroid, cause major depression disorder [93]. Studies of $7 \alpha-\mathrm{OH}$ PREG thus open a new research field in neurosteroid regulation of biological rhythms and depression.

\section{Conclusions}

The discovery of brain and pineal $7 \alpha-\mathrm{OH}$ PREG allows us to pursue new avenues in studies of behavioral neuroendocrinology across vertebrates. Based on extensive research, we now know that $7 \alpha-\mathrm{OH}$ PREG is an important bioactive neurosteroid regulating locomotor behavior. This short-review summarized the discovery, progress and prospect of brain and pineal $7 \alpha-\mathrm{OH}$ PREG regulating locomotor behavior in vertebrates. $7 \alpha-\mathrm{OH}$ PREG produced in the brain acts as a novel bioactive neurosteroid to stimulate locomotor activity (Figure 1). Interestingly, brain $7 \alpha-\mathrm{OH}$ PREG stimulates not only locomotor behavior but also sexual behavior [94-96]. The pineal gland also produces $7 \alpha-\mathrm{OH}$ PREG and ALLO as major pineal neurosteroids (Figure 2). Pineal $7 \alpha-\mathrm{OH}$ PREG acts on the brain and regulates locomotor rhythms (Figure 3). It is also becoming clear that the other major pineal neurosteroid ALLO acts on the brain to survive cerebellar Purkinje cells by suppressing the expression of caspase-3, a crucial mediator of apoptosis, during development [63]. Therefore, we need to clarify the interaction of brain and pineal neurosteroids, $7 \alpha-\mathrm{OH}$ PREG and ALL, in the regulation of brain development and functions. Furthermore, application of basic research to clinical research in these neurosteroids is needed in the field of Neuropsychiatry.

\section{Acknowledgments}

This review is dedicated to Tsutsui's beloved wife, Rieko Tsutsui. The works described in this review were supported at least partially by Grants-inAid for Scientific Research from the Ministry of Education, Science and Culture, Japan (16086206, 18107002, 22132004 and 22227002 to KT). We are grateful to the following collaborators, $M$. Matsunaga, K. Inoue, H. Miyabara, T. Koyama, Y. Ogura, S. Suzuki, S. Hara, M. Kusaka, Y. Suzuki, K. Sasahara, S. Honda, N. Harada, T. Hirota, M. Iitsuka, N. Kurabayashi, K. Kokame, R. Sato, A. Nakai, T. Miyata, Y. Fukada, Y. Yamamoto, J. H. Chang, M. Sato, H. Ueda, K. Tashiro, T. Tokita, J. L. Do Rego, J. Leprince, G. Pelletier, E.-E. Baulieu and Hubert Vaudry.

\section{References}

1. Baulieu EE. Neurosteroids: of the nervous system, by the nervous system, for the nervous system. Recent Prog. Horm. Res 52, 1-32 (1997).

2. Compagnone NA, Mellon SH. Neurosteroids: biosynthesis and function of these novel neuromodulators. Front. Neuroendocrinol 21(1), 1-56 (2000).

3. Do-Rego JL, Seong JY, Burel D, et al. Neurosteroid biosynthesis: enzymatic pathways and neuroendocrine regulation by neurotransmitters and neuropeptides. Front. Neuroendocrinol 30(3), 259-301 (2009).

4. Mellon $\mathrm{SH}$, Vaudry H. Biosynthesis of neurosteroids and regulation of their synthesis. Int. Rev. Neurobiol 46, 33-78 (2001).
5. Tsutsui K, Mellon SH. Neurosteroids in the brain neuron: Biosynthesis, action and medicinal impact on neurodegenerative disease. Central Nerv. Syst. Agents Med. Chem 6(1), 73-82 (2006).

6. Tsutsui K, Ukena K, Takase M, et al. Neurosteroid biosynthesis in vertebrate brains. Comp. Biochem. Physiol. C 124(2), 121129 (1999).

7. Tsutsui $K$, Ukena K, Usui M, et al. Novel brain function: biosynthesis and actions of neurosteroids in neurons. Neurosci. Res 36(4), 261-273 (2000).

8. Tsutsui K, Matsunaga M, Ukena K. Biosynthesis and biological actions of neurosteroids in the avian brain. Avian Poultry Biol. Rev 14, 63-78 (2003).
9. Tsutsui K, Matsunaga M, Miyabara H, et al. Neurosteroid biosynthesis in the quail brain. J. Exp. Zool. A Comp. Exp. Biol 305(9), 733-742 (2006).

10. Compagnone NA, Bulfone A, Rubenstein $\mathrm{JL}$, et al. Steroidogenic enzyme P450c17 is expressed in the embryonic central nervous system. Endocrinology 136(11), 5212-5223 (1995).

11. Corpéchot $C$, Robel $P$, Axelson M. et al. Characterization and measurement of dehydroepiandrosterone sulfate in rat brain. Proc. Natl. Acad. Sci. USA 78(8), 4704-4707 (1981).

12. Corpéchot $C$, Synguelakis $M$, Talha $S$, et al. Pregnenolone and its sulfate ester in rat brain. Brain Res 270(1), 119-125 (1983). 
13. Robel P, Baulieu EE. Neuro-steroids, $3 \beta$-hydroxy- $\Delta_{5}$-derivatives in the rodent brain. Neurochem. Int 7(6), 953-958 (1985).

14. Lanthier A, Patwardhan VV. Sex steroids and 5-en-3 beta-hydroxysteroids in specific regions of the human brain and cranial nerves. J. Steroid Biochem 25(3), 445-449 (1986).

15. Robel P, Bourreau E, Corpéchot $C$, et al. Neuro-steroids: $3 \beta$-hydroxy- $\Delta_{5}$-derivatives in rat and monkey brain. J. Steroid Biochem 27(4-6), 649-655 (1987).

16. John TM, Itoh S, George JC. On the role of the pineal in thermoregulation in the pigeon. Horm. Res 9(1), 41-56 (1978).

17. Mathur C, Prasad VV, Raju VS, et al. Steroids and their conjugates in the mammalian brain. Proc. Natl. Acad. Sci. USA 90(1), 85-88 (1993).

18. Mellon SH, Deschepper CF. Neurosteroid biosynthesis: genes for adrenal steroidogenic enzymes are expressed in the brain. Brain Res 629(2), 283-292 (1993).

19. Mensah-Nyagan AG, Feuilloley M, Dupont E, et al. Immunocytochemical localization and biological activity of 3 beta-hydroxysteroid dehydrogenase in the central nervous system of the frog. J. Neurosci 14(12), 73067318 (1994).

20. Mensah-Nyagan AG, Do-Rego JL, Feuilloley $M$, et al. In vivo and in vitro evidence for the biosynthesis of testosterone in the telencephalon of the female frog. $J$. Neurochem 67(1), 413-422 (1996).

21. Mensah-Nyagan AG, Feuilloley M, DoRego JL, et al. Localization of 17betahydroxysteroid dehydrogenase and characterization of testosterone in the brain of the male frog. Proc. Natl. Acad. Sci. USA 93(4), 1423-1428 (1996).

22. Mensah-Nyagan AG, Do-Rego JL, Beaujean $D$, et al. Neurosteroids: expression of steroidogenic enzymes and regulation of steroid biosynthesis in the central nervous system. Pharmacol. Rev 51(1), 63-81 (1999).

23. Takase M, Ukena $K$, Yamazaki T, et al. Pregnenolone, pregnenolone sulfate and cytochrome P450 side-chain cleavage enzyme in the amphibian brain and their seasonal changes. Endocrinology 140(4), 1936-1944 (1999).

24. Takase M, Ukena K, Tsutsui K. Expression and localization of cytochrome P45011 $\beta$, aldo $m R N A$ in the frog brain. Brain Res 950(1-2), 288-296 (2002).

25. Takase M, Haraguchi S, Hasunuma I, et al. Expression of cytochrome P450 side-chain cleavage enzyme mRNA in the brain of the Red-bellied newt Cynops pyrrhogaster. Gen. Comp. Endocrinol 170(3), 468-474 (2011).
26. Tsutsui K, Yamazaki T. Avian neurosteroids I Pregnenolone biosynthesis in the quail brain. Brain Res 678(1-2), 1-9 (1995).

27. Usui M, Yamazaki T, Kominami S, et al. Avian neurosteroids. II. Localization of a cytochrome P450scc-like substance in the quail brain. Brain Res 678(1-2), 10-20 (1995).

28. Vanson A, Arnold AP, Schlinger BA. $3 \beta$-Hydroxysteroid dehydrogenase/ isomerase and aromatase activity in primary cultures of developing zebra finch telencephalon: dehydroepiandrosterone as substrate for synthesis of androstenedione and estrogens. Gen. Comp. Endocrinol 102(3), 342-350 (1996).

29. Tsutsui K, Yamazaki T, Usui M, et al. P450scc activity in the brain. In: Harvey S, Etches RJ. Perspectives in avian endocrinology. Bristol: J Endocrinol Ltd 427-436 (1997).

30. Rose KA, Stapleton G, Dott K, et al. Cyp7b, a novel brain cytochrome $\mathrm{P} 450$, catalyzes the synthesis of neurosteroids 7a-hydroxy dehydroepiandrosterone and 7a-hydroxy pregnenolone. Proc. Natl. Acad. Sci. USA 94(10), 4925-4930 (1997).

31. Ukena $K$, Honda $Y$, Inai $Y$, et al. Expression and activity of $3 \beta$-hydroxysteroid dehydrogenase $/ \Delta^{5}-\Delta^{4}$-isomerase in different regions of the avian brain. Brain Res 818(2), 536-542 (1999).

32. Ukena K, Honda Y, Lea RW, et al. Developmental changes in progesterone biosynthesis and metabolism in the quail brain. Brain Res 898(1), 190-194 (2001).

33. Beaujean D, Mensah-Nyagan AG, Do-Rego $\mathrm{JL}$, et al. Immunocytochemical localization and biological activity of hydroxysteroid sulfotransferase in the frog brain. $J$. Neurochem 72(2), 848-857 (1999).

34. Schlinger BA, Lane NI, Grisham W, et al. Androgen synthesis in a songbird: a study of cyp17 (17a-hydroxylase/c17,20-lyase) activity in the zebra finch. Gen. Comp. Endocrinol 113(1), 46-58 (1999).

35. Freking F, Nazairians T, Schlinger BA. The expression of the sex steroid-synthesizing enzymes CYP11A1, 3beta-HSD, CYP17, and CYP 19 in gonads and adrenals of adult and developing zebra finches. Gen. Comp. Endocrinol 119(2), 140-151 (2000).

36. Tsutsui K, Schlinger BA. Steroidogenesis in the avian brain. In: Dawson A, Chaturvedi CM. Avian endocrinology. New Delhi: Narosa Publishing House, India 59-77 (2001).

37. Matsunaga M, Ukena $K$, Tsutsui $K$. Expression and localization of the cytochrome P450 17a-hydroxylase/c17,20lyase in the avian brain. Brain Res 899(1-2), 112-122 (2001).
38. Matsunaga M, Ukena K, Tsutsui K. Androgen biosynthesis in the quail brain. Brain Res 948(1-2), 180-185 (2002)

39. Sakamoto H, Ukena K, Tsutsui K. Activity and localization of $3 \beta$-hydroxysteroid dehydrogenase $/ \Delta^{5}-\Delta^{4}$-isomerase in the zebrafish central nervous system. J. Comp. Neurol 439(3), 291-305 (2001).

40. Inai $Y$, Nagai $K$, Ukena $K$, et al. Seasonal changes in neurosteroids in the urodele brain and environmental factors inducing their changes. Brain Res 959(2), 214-225 (2003)

41. Matsunaga M, Ukena K, Baulieu EE, et al. 7a-Hydroxypregnenolone acts as a neuronal activator to stimulate locomotor activity of breeding newts by means of the dopaminergic system. Proc. Natl. Acad. Sci. USA 101(49), 17282-17287 (2004).

42. London SE, Boulter J, Schlinger BA. Cloning of the zebra finch androgen synthetic enzyme CYP17: a study of its neural expression throughout posthatch development. J. Comp. Neurol 467(4), 496508 (2003).

43. London S, Monks DA, Wade J, et al. Widespread capacity for steroid synthesis in the avian brain and song system. Endocrinology 147(12), 5975-5987 (2006).

44. London E, Itoh Y, Lance VA, et al. Neural expression and post-transcriptional dosage compensation of the steroid metabolic enzyme 17区-HSD type 4. BMC Neurosci 11, 47 (2010).

45. Soma KK, Alday NA, Hau M, et al. Dehydroepiandrosterone metabolism by $3 \beta$-hydroxysteroid dehydrogenase/ $\Delta^{5}$ - $\Delta^{4}$-isomerase in adult zebra finch brain: sex difference and rapid effect of stress. Endocrinology 145(4), 1668-1677 (2004).

46. Menuet A, Pellegrini E, Brion F, et al. Expression and estrogen-dependent regulation of the zebrafish brain aromatase gene. J. Comp. Neurol 485(4), 304-320 (2005).

47. Do-Rego JL, Tremblay Y, Luu-The V, et al. Immunocytochemical localization and biological activity of the steroidogenic enzyme cytochrome P450 17a-hydroxylase/ $\mathrm{C} 17,20$-lyase $\left(\mathrm{P} 45 \mathrm{C}_{\mathrm{C1}}\right)$ in the frog brain and pituitary. J. Neurochem 100(1), 251-268 (2007).

48. London S, Schlinger BA. Steroidogenic enzymes along the ventricular proliferative zone in the developing songbird brain. J. Comp. Neurol 502(4), 507-521 (2007).

49. Tam H, Schlinger BA. Activities of 3 $\beta-H S D$ and aromatase in slices of developing and adult zebra finch brain. Gen. Comp. Endocrinol 150(1), 26-33 (2007). 
50. Bruzzone F, Do-Rego JL, Luu-The V, et al. Immunohistochemical localization and biological activity of $3 \beta$-hydroxysteroid dehydrogenase and $5 a$-reductase in the brain of the frog, Rana esculenta, during development. J. Chem. Neuroanat 39(1), 35-50 (2010).

51. Brion F, Le Page Y, Piccini B, et al. Screening estrogenic activities of chemicals or mixtures in vivo using transgenic (cyp19a1b-GFP) zebrafish embryos. PLoS ONE 7 e36069 (2012).

52. Diotel N, Do-Rego JL, Anglade I, et al. Activity and expression of steroidogenic enzymes in the brain of adult zebrafish. Eur. J. Neurosci 34(1), 45-56 (2011).

53. Haraguchi S, Koyama T, Hasunuma I, et al. Prolactin increases the synthesis of 7a-hydroxypregnenolone, a key factor for induction of locomotor activity, in breeding male newts. Endocrinology 151(5), 2211-2222 (2010).

54. Tsutsui K, Inoue K, Miyabara H, et al. 7a-hydroxypregnenolone mediates melatonin action underlying diurnal locomotor rhythms. J. Neurosci 28(9), 21582167 (2008).

55. Haraguchi S, Yamamoto $Y$, Suzuki Y, et al. 7a-Hydroxypregnenolone, a key neuronal modulator of locomotion, stimulates upstream migration by means of the dopaminergic system in salmon. Sci. Rep 5, 12546 (2015)

56. Tsutsui K, Haraguchi S, Inoue K, et al. Identification, biosynthesis, and function of 7a-hydroxypregnenolone, a new key neurosteroid controlling locomotor activity, in nonmammalian vertebrates. Ann. NY Acad. Sci 1163, 308-315 (2009).

57. Tsutsui, K., Inoue, K., Miyabara, H, et al. Discovery of a novel avian neurosteroid, 7a-hydroxypregnenolone, and its role in the regulation of the diurnal rhythm of locomotor activity in Japanese quail. Gen. Comp. Endocrinol 163(1-2), 117-122 (2009).

58. Tsutsui $K$, Haraguchi $S$, Matsunaga $M$, et al. 7a-hydroxypregnenolone, a new key regulator of locomotor activity of vertebrates: identification, mode of action, and functional significance. Front. Endocrinol 1, 9 (2010).

59. Tsutsui K, Haraguchi S, Matsunaga M, et al. Identification of 7a-hydroxypregnenolone, a novel bioactive amphibian neurosteroid stimulating locomotor activity, and its physiological roles in the regulation of locomotion. Gen. Comp. Endocrinol 168(2), 275-279 (2010)

60. Tsutsui K, Haraguchi S, Matsunaga M, et al. 7a-Hydroxypregnenolone, a new key regulator of amphibian locomotion: discovery, progress and prospect. Gen. Comp. Endocrinol 176(3), 440-447 (2012).
61. Tsutsui K, Haraguchi S, Fukada Y, et al. Brain and pineal $7 a$-hydroxypregnenolone stimulating locomotor activity: identification, mode of action and regulation of biosynthesis. Front. Neuroendocrinol 34(3), 179-189 (2013).

62. Tsutsui K, Haraguchi S, Hatori M, et al. Biosynthesis and biological actions of pineal neurosteroids in domestic birds. Neuroendocrinology 98(2), 97-105 (2013).

63. Haraguchi S, Hara S, Ubuka T, et al. Possible role of pineal allopregnanolone in Purkinje cell survival. Proc. Natl. Acad. Sci. USA 109(51), 21110-21115 (2012).

64. Hatori M, Hirota T, litsuka M, et al. Lightdependent and circadian clock-regulated activation of sterol regulatory elementbinding protein, $X$-box-binding protein 1 , and heat shock factor pathways. Proc. Natl. Acad. Sci. USA 108(12), 4864-4869 (2011).

65. Akwa Y, Morfin RF, Robel P, et al. Neurosteroid metabolism: 7a-Hydroxylation of dehydroepiandrosterone and pregnenolone by rat brain microsomes. Biochem. J 288(Pt3), 959-964 (1992).

66. Doostzadeh J, Morfin R. Effects of cytochrome P450 inhibitors and of steroid hormones on the formation of 7-hydroxylated metabolites of pregnenolone in mouse brain microsomes. J. Endocrinol 155(2), 343-350 (1997).

67. Weill-Engerer S, David JP, Sazdovitch $V$, et al. In vitro metabolism of dehydroepiandrosterone (DHEA) to 7a-hydroxy-DHEA and $\Delta^{5}$-androstene- $3 \beta, 17 \beta$ diol in specific regions of the aging brain from Alzheimer's and non-demented patients. Brain Res 969(1-2), 117-125 (2003).

68. Yau JL, Rasmuson S, Andrew R, et al. Dehydroepiandrosterone 7-hydroxylase CYP7B: predominant expression in primate hippocampus and reduced expression in Alzheimer's disease. Neuroscience 121(2), 307314 (2003).

69. Gowans ARD, Armstrong JD, Priede IG, et al. Movements of Atlantic salmon migrating upstream through a fish-pass complex in Scotland. Ecol. Freshw. Fish 12(3), 177-189 (2003).

70. Makiguchi Y, Nii H, Nakao K, et al. Migratory behaviour of adult chum salmon, Oncorhynchus keta, in a reconstructed reach of the Shibetsu River, Japan. Fish. Manag. Ecol 15(5-6), 425-433 (2008).

71. Weatherley AH, Rogers SC, Pincock DG, et al. Oxygen consumption of active rainbow trout, Salmo gairdneri Richardson, derived from electromyograms obtained by radiotelemetry. J. Fish Biol 20(4), 479-489 (1982).

72. Tsutsui K, Haraguchi S, Inoue K, et al. New biosynthesis and biological actions of avian neurosteroids. J. Exp. Neurosci 7, 15-29 (2013).
73. Binkley S, Kluth E, Menaker M. Pineal function in sparrows: circadian rhythms and body temperature. Science 174(4006), 311-314 (1971).

74. Cassone VM, Menaker M. Is the avian circadian system a neuroendocrine loop? J. Exp. Zool 232(3), 539-549 (1984).

75. Chabot CC, Menaker M. Circadian feeding and locomotor rhythms in pigeons and house sparrows. J. Biol. Rhythms 7(4), 287-299 (1992).

76. Hau M, Gwinner E. Melatonin facilitates synchronization of sparrow circadian rhythms to light. J. Comp. Physiol. A 175(3), 343-347 (1994).

77. Murakami N, Kawano T, Nakahara K, et al. Effect of melatonin on circadian rhythm, locomotor activity and body temperature in the intact house sparrow, Japanese quail and owl. Brain Res 889(1-2), 220-224 (2001).

78. Warren WS, Cassone VM. The pineal gland: photoreception and coupling of behavioral, metabolic, and cardiovascular circadian outputs. J. Biol. Rhythms 10(1), 64-79 (1995).

79. Kano $Y$, Nakano T, Kumakura M, et al. Seasonal expression of $\mathrm{LH} \beta$ and $\mathrm{FSH} \beta$ in the male newt pituitary gonadotrophs. Gen. Comp. Endocrinol 141(3), 248-258 (2005).

80. Matsuda K, Tanaka S, Yamamoto K, et al. Annual changes of plasma prolactin levels in the newt, Cynops pyrrhogaster. Zool. Sci 7(6), 1143 (1990).

81. Mosconi G, Yamamoto K, Kikuyama S, et al. Seasonal changes of plasma prolactin concentration in the reproduction of the crested newt (Triturus carnifex Laur). Gen. Comp. Endocrinol 95(3), 342-349 (1994).

82. Breuner CW, Greenberg AL, Wingfield JC. Noninvasive corticosterone treatment rapidly increases activity in gambel's white-crowned sparrows (Zonotrichia leucophrys gambelii). Gen. Comp. Endocrinol 111(3), 386-394 (1998).

83. Breuner CW, Wingfield JC. Rapid behavioral response to corticosterone varies with photoperiod and dose. Horm. Behav 37(1), 23-30 (2000).

84. Mitra R, Sapolsky RM. Acute corticosterone treatment is sufficient to induce anxiety and amygdaloid dendritic hypertrophy. Proc. Natl. Acad. Sci. USA 105(14), 5573-5578 (2008).

85. Moore FL, Miller LJ. Stress-induced inhibition of sexual behavior: Corticosterone inhibits courtship behaviors of a male amphibian (Taricha granulosa). Horm. Behav 18(4), 400410 (1984).

86. Ricciardella LF, Bliley JM, Feth CC, et al. Acute stressors increase plasma corticosterone and decrease locomotor activity in a terrestrial salamander (Desmognathus ochrophaeus). Physiol. Behav 101(1), 81-86 (2010). 
87. Hubbard CS, Dolence EK, Rose JD. Brainstem reticulospinal neurons are targets for corticotropin-releasing factorInduced locomotion in roughskin newts. Horm. Behav 57(2), 237-246 (2010).

88. Lee EH, Tsai MJ, Chai CY. Stress selectively influences center region activity of mice in an open field. Physiol. Behav 37(4), 659-662 (1986).

89. Haraguchi S, Koyama T, Hasunuma I, et al. Acute stress increases the synthesis of 7a-hydroxypregnenolone, a new key neurosteroid stimulating locomotor activity, through corticosterone action in newts. Endocrinology 153(2), 794-805 (2012).
90. Fukada Y, Okano T. Circadian clock system in the pineal gland. Mol. Neurobiol 25(1), 19-30 (2002).

91. Hirota T, Fukada Y. Resetting mechanism of central and peripheral circadian clocks in mammals. Zool. Sci 21(4), 359-368 (2004).

92. Pandi-Perumal SR, Trakht I, Srinivasan V et al. Physiological effects of melatonin: role of melatonin receptors and signal transduction pathways. Prog. Neurobiol 85(3), 335-353 (2008).

93. Herbert J. Cortisol and depression: three questions for psychiatry. Psychol. Med 43(3), 449-469 (2013).
94. Toyoda F, Haraguchi S, Tsutsui K, et al. Involvement of a neurosteroid, 7a-hydroxypregnenolone in the courtship behavior performed by the male newt, Cynops pyrrhogaster. Horm. Behav 62(4), 375-380 (2012).

95. Toyoda F, Haraguchi S, Tsutsui K, et al. Possible hormonal interaction for eliciting courtship behavior in the male newt, Cynops pyrrhogaster. Gen. Comp. Endocrinol 224 (12), 96-13 (2015).

96. Ogura Y, Haraguchi S, Tsutsui K. 7a-Hydroxypregnenolone regulates diurnal changes in sexual behavior of male quail. Gen. Comp. Endocrinol 227(2), 130-135 (2016). 